\title{
CARACTERIZAÇÃO DE VASOS SANGUÍNEOS ARTIFICIAIS DE CELULOSE BACTERIANA
}

\author{
F. P. ROTUNNO ${ }^{1}$, G. COLLA $^{1}$ e L. M. PORTO ${ }^{1}$ \\ ${ }^{1}$ Universidade Federal de Santa Catarina, \\ Departamento de Engenharia Química e Engenharia de Alimentos \\ E-mail para contato: \{fernandarotunno, guilherme_colla, luismar\}@intelab.ufsc.br
}

\begin{abstract}
RESUMO - O desenvolvimento de scaffolds para a engenharia de tecidos vem ganhando importância à medida que novos dispositivos celularizados tem sido eficientemente testados e validados tanto in vitro quanto in vivo. Atualmente, um dos maiores desafios da engenharia de tecidos e da engenharia de órgãos é a disponibilização de vasos sanguíneos artificiais que possam mimetizar vasos sanguíneos nativos com sucesso. Esses dispositivos podem ser utilizados para validar experimentos relacionados à resposta a novos medicamentos e para o desenvolvimento de vasos sanguíneos para implantes (bypass), entre outros. O objetivo desse trabalho é biossintetizar vasos sanguíneos artificiais de celulose bacteriana, produzida pela bactéria Gluconacetobacter xylinus, e testar suas características funcionais e estruturais. A observação por MEV mostrou uma membrana constituída de fibras densas formadas na interface com o ar (interior do vaso), seguida por uma superfície porosa (exterior do vaso). O ensaio à tração mostrou uma tensão de ruptura comparável a de um vaso sanguíneo humano. Dessa forma, esse estudo apresenta um biomaterial com potenciais aplicações na engenharia de tecidos como um modelo de vasos sanguíneos.
\end{abstract}

\section{INTRODUÇÃO}

Doenças vasculares ateroscleróticas ainda são as maiores causas de morte nas sociedades ocidentais. De acordo com a Organização Mundial da Saúde, o número de vítimas chega a 17,3 milhões de pessoas por ano (Mendis et al., 2011). Mais de 600.000 procedimentos cirúrgicos são feitos a cada ano pelo Mundo utilizando enxertos vasculares de até $6 \mathrm{~mm}$ de diâmetro. Ainda que vasos autólogos continuem sendo os mais usados, parte dos pacientes não possui vasos apropriados devido a doenças vasculares, amputação, entre outros motivos. Além disso, para fazer o enxerto é necessário fazer um segundo procedimento cirúrgico, o que pode aumentar os riscos para o paciente (Scherner et al., 2014).

Vasos sanguíneos artificiais produzidos a partir de diversos materiais já vêm sendo testados com o objetivo de substituir o uso de enxertos, como é o caso do ácido hialurônico esterificado (Remuzzi et al., 2004), de uma matriz extracelular natural de membrana amniótica (Lee et al., 2012) e da fibroína de seda (Zhang et al., 2009), por exemplo. Vasos de celulose bacteriana de até 1 mm de diâmetro já estão sendo usados em microcirurgias, tanto como capa protetora para suturas de micronervos quanto na forma de modelo prático para o treinamento de suturas (Klemm et al., 2001). 
A celulose bacteriana (CB) é produzida em forma de fibra por algumas bactérias do gênero Gluconacetobacter quando cultivadas em um meio de cultura com fontes de carbono e nitrogênio (Brown et al., 1976). A Gluconacetobacter xylinus (anteriormente Acetobacter xylinum) é uma bactéria Gram-negativa capaz de polimerizar cadeias lineares de $\beta$-1,4-glucana que são então secretadas para o exterior da célula (Czaja e Krystynowic, 2006). A CB sintetizada pela G. xylinus apresenta diversas características únicas, como alta biocompatibilidade, alta permeabilidade e capacidade de retenção de água e resistência mecânica (Klemm et al., 2005). Esse tipo de celulose é idêntico à celulose de origem vegetal em termos de estrutura molecular. No entanto, a celulose bacteriana é livre de lignina, pectina e hemicelulose. Esse biomaterial possui várias aplicações no campo biomédico (Czaja et al., 2007), como pele artificial, curativo, vasos sanguíneos artificiais, dispositivos para a engenharia de tecidos (Gao et al., 2011), entre outras.

As características citadas anteriormente indicam que a celulose bacteriana é um biomaterial com grande potencial para aplicação na engenharia de tecido vascular. Dessa forma, o objetivo deste trabalho é biossintetizar vasos de hidrogel de celulose bacteriana com $4 \mathrm{~mm}$ de diâmetro, utilizando a bactéria G. xylinus, e testar suas características funcionais e estruturais.

\section{METODOLOGIA}

\subsection{Produção do inóculo}

Foram colocados $80 \mathrm{~mL}$ de meio Hestrin \& Schramm (HS) em um Erlenmeyer de $100 \mathrm{~mL}$ previamente autoclavado e tampado com uma bucha estéril. Em seguida, foram adicionados 20 $\mathrm{mL}$ de inóculo G. xylinus. Após a reativação da bactéria, o inóculo foi mantido por um período de quatro dias para posterior utilização.

\subsection{Produção dos vasos}

Em um frasco schott estéril foi colocado o meio HS, inoculado com 20\% G. xylinus, totalizando $400 \mathrm{~mL}$. A suspensão foi então transferida a um Erlenmeyer estéril de $500 \mathrm{~mL}$, com uma mangueira de silicone de $4 \mathrm{~mm}$ de diâmetro externo colocada dentro dele. Com uma bucha estéril, essa mangueira foi fixada de forma que ficasse submersa no meio sem entrar em contato com as paredes ou com o fundo do recipiente. A mangueira foi conectada a uma bomba de circulação de ar e, dessa forma, a membrana foi produzida em torno da mangueira devido à porosidade do silicone. Utilizando esse método, o vaso foi biossintetizado por um período de 12 dias. O silicone foi retirado do interior do vaso, a membrana foi limpa com $\mathrm{NaOH} 0,1 \mathrm{M}$, seu pH foi estabilizado e, por fim, ela foi esterilizada.

\subsection{Caracterização estrutural dos vasos}

Os vasos de celulose bacteriana foram liofilizados $\left(-80{ }^{\circ} \mathrm{C}\right.$, por $\left.24 \mathrm{~h}\right)$ antes de serem submetidos à análise por microscopia eletrônica de varredura (MEV) no Laboratório Central de Microscopia (LCME) utilizando-se o equipamento JEOL JSM - 6390LV. 


\subsection{Caracterização funcional dos vasos}

Os vasos de celulose bacteriana foram submetidos a um ensaio à tração utilizando o texturômetro Stable Micro Systems. Foram realizadas cinco repetições de cada amostra, de dimensões: $50 \mathrm{~mm}$ de comprimento e diâmetro de $4 \mathrm{~mm}$. A espessura obtida dos biofilmes foi $1,2 \pm 0,3 \mathrm{~mm}$, considerando-se a média de cinco medidas repetidas aleatoriamente. A separação inicial entre as garras e a velocidade do teste foi de $40 \mathrm{~mm}$ e $0,5 \mathrm{~mm} \cdot \mathrm{s}^{-1}$, respectivamente.

\section{RESULTADOS E DISCUSSÃO}

A bactéria Gluconacetobacter xylinus, quando cultivada em meio de cultura HS em condições estáticas de cultura, produz membranas de celulose na interface líquido/ar. Essa membrana é formada por um grande número de camadas de celulose finas e cresce em espessura para dentro do meio líquido (Borzani e Souza, 1995). Os vasos de CB produzidos neste trabalho apresentaram as dimensões de $10 \mathrm{~cm}$ de comprimento, $4 \mathrm{~mm}$ de diâmetro e 1,2 $\pm 0,3 \mathrm{~mm}$ de espessura.

As amostras liofilizadas foram caracterizadas quanto à sua microestrutura, por microscopia eletrônica de varredura (MEV). A microestrutura da membrana de celulose bacteriana obtida através do corte transversal da amostra indica que a superfície do interior do vaso, parte que fica na interface com o ar proveniente do bombeamento, apresenta alta densidade de nanofibras de celulose, enquanto que a superfície do exterior do vaso, parte que fica na interface com o meio de cultura HS, é caracterizada por uma rede de nanofibras com baixa densidade, conforme mostra a Figura 1.
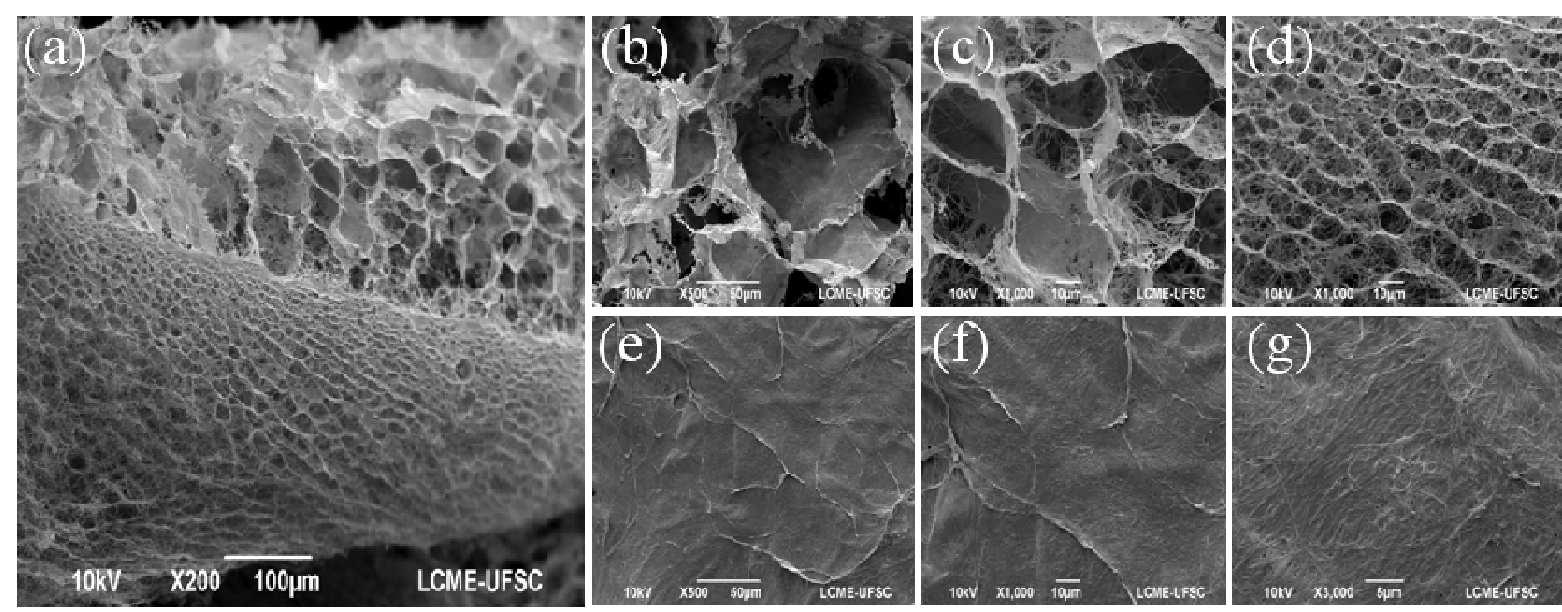

Figura 1 - (a) Membrana de celulose bacteriana formada por superfície porosa seguida por uma superfície densa. (b), (c) e (d) mostram detalhes da superfície porosa; (e), (f) e (g) mostram detalhes da superfície densa. 
Os vasos de celulose bacteriana foram submetidos a ensaios mecânicos enquanto estavam no estado hidratado para verificar a tensão de ruptura, o módulo de elasticidade de Young e o alongamento relativo sob tensão antes da ruptura. O resultado do ensaio à tração pode ser observado na Figura 2, que mostra uma curva típica de tensão-deformação para os vasos quando expostos a uma tensão.

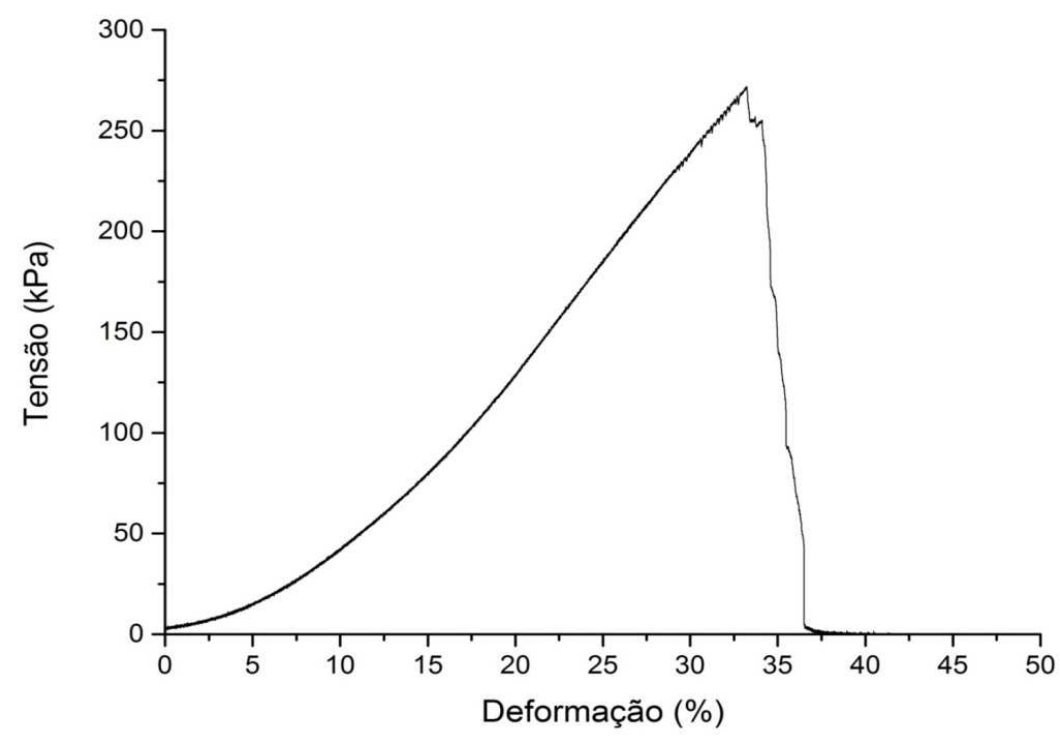

Figura 2: Curva de tensão versus deformação do vaso de celulose bacteriana hidratado.

O valor da tensão de ruptura da celulose bacteriana enquanto estava em forma tubular e hidratada se mostrou superior aos valores disponíveis na literatura tanto para a veia safena (Roeder et al., 1999) quanto para a artéria carótida (Latimer et al., 2013). O módulo de elasticidade de Young obtido, que indica a rigidez do material, foi inferior ao módulo de elasticidade da safena e da carótida, como pode ser observado na Tabela 1. Ainda assim, esse biomaterial é resistente e capaz de suportar a pressão arterial à qual seria submetido.

Tabela 1 - Comparação entre os dados obtidos com o ensaio à tração e os dados da literatura referentes à veia safena e à artéria carótida

\begin{tabular}{ccc}
\hline & Tensão de Ruptura $(\mathrm{kPa})$ & Módulo de Elasticidade $(\mathrm{kPa})$ \\
\hline Vaso de CB & $229 \pm 38$ & $10,46 \pm 0,63$ \\
Veia Safena & 131 & 550 \\
Artéria Carótida & 56,4 & 40 \\
\hline
\end{tabular}




\section{CONCLUSÕES}

O presente estudo demonstrou a viabilidade de produção de vasos artificiais de celulose bacteriana de pequeno calibre, material de grande demanda para a substituição de vasos coronários. Foram produzidos e caracterizados vasos artificiais de $4 \mathrm{~mm}$ de diâmetro e até $15 \mathrm{~cm}$ de comprimento. O biomaterial produzido é resistente, capaz de suportar a pressão arterial coronariana, e pode ser potencialmente utilizado como substituto de veias safenas e artérias mamárias em cirurgias de bypass, visando à revascularização do miocárdio, assim como substituição de outros vasos sanguíneos. O método de produção desenvolvido permite a construção de vasos de diâmetro e espessura variáveis.

\section{REFERÊNCIAS}

BORZANI, W.; SOUZA, S. Mechanism of the film thickness increasing during the bacterial production of cellulose on non-agitaded liquid media. Biotechnol. Lett., v. 17, n. 11, p. 1271-1272, 1995/11/01 1995.

BROWN JR., R.M.; WILLISON, J.H.M.; RICHARDSON, C.L. "Cellulose biosynthesis in Acetobacter xylinum”. P. Natl. Acad. Sci. USA., p. 4565 - 4569, 1976.

CZAJA, W.; KRYSTYNOWICZ, A. "Microbial cellulose - the natural power to heal wounds". Biomaterials, p. 145-151, 2006.

CZAJA, W.K.; YOUNG, D.J.; KAWECKI, M.; BROWN, R.M. "The future prospects of microbial cellulose in biomedical applications." Biomacromolecules, p. 1-12, 2007.

GAO, C.A.; WAN, Y.Z.; YANG, C.X.; DAI, K.R.; TANG, T.T.; LUO, H.L. "Preparation and characterization of bacterial cellulose sponge with hierarchical pore structure as tissue engineering scaffold." J. Porous. Mat., p. 139-145, 2011.

KLEMM, D.; HEUBLEIN, B.; FINK, H.P.; BOHN, A. "Cellulose: Fascinating biopolymer and sustainable raw material.” Angewandte Chemie International Edition, p. 3358-3393, 2005.

KLEMM, D.; SCHUMANN, D.; UDHARDT, U.; MARSCH, S. "Bacterial synthetized cellulose artificial blood vessels for microsurgery”. Prog. Polym. Sci., p. 1561-1603, 2001.

LATIMER, C.A.; NELSON, M.; MOORE, C.; M.; MARTIN, K.E. "Effect of collagen and elastin content on the burst pressure of human blood vessel seals formed with a bipolar tissue sealing system". J. Surg. Res., p. 1 -8. 2013.

LEE, P.H.; TSAI, S.H.; KUO, L.; HWANG, C.Y.; KUO, C.Y.; YANG, V. C.; CHEN, J.K. “A prototype tissue engineered blood vessel using amniotic membrane as scaffold". Acta. Biomater. 2012. 
MENDIS, S.; PUSKA, P.; NORRVING, B. Global Atlas on Cardiovascular Disease Prevention and Control Geneva: World Health Organization, 2011.

REMUZZI, A.; MANTERO, S.; COLOMBO, M.; MORIGI, M.; BINDA, E.; CAMOZZI, D.; IMBERTI, B. "Vascular smooth muscle cells on hyaluronic acid: culture and mechanical characterization of an engineered vascular construct". Tissue. Eng., v.10, n.5-6, p.699-710. 2004.

ROEDER, R.; WOLFE, J.; LIANAKIS, N.; HINSON, T.; GEDDES, L. A.; OBERMILLER, J. "Compliance, elastic modulus, and burst pressure of small-intestine submucosa (SIS), smalldiameter vascular grafts". J. Biomed. Mater. Res., v.47, n.1, p.65-70. 1999.

SCHERNER, M.; REUTTER, S.; KLEMM, D.; STERNET-KOCK, A.; GUSCHLBAUER, M.; RICHTER, T.; LANGEBARTELS, G.; MADERSHAHIAN, N.; WAHLERS, T.; WIPPERMANN, J. "In vivo application of tissue-engineered bloods vessels of bacterial cellulose as small arterial substitutes: proof of concept?” J. Surg. Res., 2014.

ZHANG, X.; WANG, X.; KESHAV, V.; WANG, X.; JOHANAS, J. T.; LEISK, G. G.; KAPLAN, D. L. "Dynamic culture conditions to generate silk-based tissue-engineered vascular grafts". Biomaterials, v.30, n.19, p.3213-3223. 2009. 